\title{
Trust, Risk and Alternative Website Quality in B-Buyer Acceptance of Cross-Border E-Commerce
}

\author{
Jian Mou, Xidian University, Xi'an, China \\ Yi Cui, Communication University of China, Beijing, China \\ Kerry Kurcz, University of Illinois at Chicago, Chicago, USA
}

\begin{abstract}
Cross-border e-commerce (CBEC) has become an imperative mode for global trade. Research on cross-border e-commerce historically focuses mainly on the customer's behavior intention to purchase on a CBEC platform. However, B-buyers are more important compared with C-buyers for CBEC platforms. This is because B-buyers can contribute more gross merchandise volume (GMV) in a CBEC platform, and thus more margin for the firm. The authors apply trust transfer theory, perceived risk, and alternative website quality to study repurchase intention, focusing on B-buyers. The results show that perceived risk, trust in provider, and trust in the website affect repurchase intention significantly, where trust in website is found to be the most important factor. In addition, the authors found that the dimensions of perceived risk in CBEC context can be classified as the following: customer duties risk, confiscation risk, delivery risk, financial risk, and privacy risk. The contributions of the study are addressed lastly.
\end{abstract}

\section{KEYWORDS}

B-Buyers, CBEC, Cross-Border E-Commerce, Perceived Risk, Repurchase Intention, Trust

\section{INTRODUCTION}

With the flourish of internet technology, information technology, logistic services and globalization of world trade, e-consumers tend to look beyond their borders. Global e-commerce sales reached 6.3 trillion yuan (about 914 billion U.S. dollars) in 2016 alone, based on the data from the Ministry of Commerce (Ministry of Commerce, 2017). Research reports from iResearch (2017), a professional consultancy company concentrating on online media and e-commerce, also predict that this total turnover will nearly double to 12 trillion yuan (about 1.74 trillion U.S. dollars) by 2020 . By that time, $39 \%$ of the world's entire e-commerce market will be controlled by traditional marketplaces, and $53 \%$ of cross-border sellers in the US will use online marketplaces. Such rapid development indicates the immense potential and opportunity of cross-border e-commerce (CBEC) for global economics to grow in the near future. Therefore, CBEC research plays an important role for economic development-globally. Given the importance of CBEC, understanding and dedicating special attention to the factors that influence buyers' behavior is essential for any company who wishes to survive and thrive among the exponential trends of globalization.

Many studies have shown trust is priority in the setting of any e-commerce. However, in CBEC, trust becomes even more crucial due to the "distance" between buyers and sellers, where "distance" 
has been recognized as language barriers, legal systems barrier, time barrier, delivery services, as well as customs regulations (Kim, Dekker, \& Heij, 2017). Although multi-dimensional trust has been investigated in the e-commerce setting, there is a lack of evidence in the effect of multi-dimensional trust in the CBEC context. CBEC is different from domestic e-commerce. These differences mainly reveal additional trade costs and risks from cross-border transport, import tariffs, differences in technical standards, poor institutional quality and weak contract enforcement (Gomez-Herrera, Martens, \& Turlea, 2014).

Given the complex nature of CBEC, its buyers are more likely to perceive risks. Multiple factor risks have been considered in the domestic e-commerce setting (e.g., Tandon, Kiran, \& Sah, 2018; Marriott \& Williams, 2018), albeit risks such as customer duties risk, confiscation risk, delivery risk have yet to be deeply investigated in CBEC. Therefore, understanding perceived risk in studying CBEC is necessary. Furthermore, most existing research focuses on C-buyers, while B-buyers are more important for CBEC platform. This is because B-buyers can contribute more margin for a firm (Kraemer, Gibbs, \& Dedrick, 2005). In this research, B-buyers refer to customers who buy products or services for the company or workplace with which they belong. In fact, B2C transactions have developed rapidly in recent years due to the convenience of high discounts. Meanwhile, B2B transactions are growing four times faster than their B2C counterpart (Vakeel, Das, Udo, \& Bagchi, 2017). However, and perhaps most importantly, it has been proven that B-buyers contribute more Gross Merchandise Volume (GMV) in CBEC platforms. Compared to B2C e-commerce, B2B e-commerce is a less researched area with significant difference about transaction volume, average transaction amount, logistics, customer segments, fulfilment issues, and advertisement objectives (Vakeel et al., 2017). Another convenient characteristic of B-buyers is that they are more likely to transact with their previous sellers, with the same items, in large volumes. Meanwhile, Kraemer et al. (2005) emphasized that for B2B e-commerce, highly global companies utilize the Internet more than their less global counterparts, whereas for $\mathrm{B} 2 \mathrm{C}$ e-commerce the opposite is true. This is because global companies focus more on wholesale brokerage activity in different countries across various stages of an industry's value chain, while less global companies focusing on the retail brokerage industry are less affected by globalization, and thus remain local.

Since B-buyers are more likely to purchase products in a wholesale setting, alternative quality such as service quality and system quality are more important for B-buyers. Furthermore, they normally query several CBEC platforms among multiple sellers, seeking out the lowest price for dozens of products. For any type of consumer, alternative website quality can make all the difference in switching behavior and trust in that website (Sørum, 2015; Kalia, Arora, \& Kumalo, 2016). CBEC platforms constantly need to improve their quality of products-while keeping prices low--and attract more international buyers with the opportunity of promotional days (such as Christmas or Black Friday). Indeed, the perceptions rising from alternative platforms is to be among the top priorities regarding CBEC research.

In general, this paper aims to integrate perceived risk and alternative website quality to understand the crucial trust-building mechanism for promoting repurchase behavior as well as enhancing CBEC platform loyalty. Moreover, this paper strives to bridge the gap between trust and CBEC with the antecedents of trust, and to uncover why some CBEC platforms succeed, while others do not (as with Metao.com, which will see later). These findings may help researchers to extend their studies and, of course, practitioners to make their website more attractive to buyers. These points are summed up with the following research question:

RQ: Will alterative website quality, perceived risk and trust jointly affect the consumer's repurchase intention in CBEC?

The structure of this study is organized as follows: the first section reviews existing CBEC literature and the current theoretical background; section two demonstrates the development of the research model and hypothesis; this is followed by the design of this study; then the research results; last, the paper concludes with discussions, contributions and limitations. 


\section{LITERATURE REVIEW AND HYPOTHESIS DEVELOPMENT}

\section{Cross-Border E-commerce}

CBEC generally refers to transactions among different countries or customs areas through an e-commerce platform and cross-border logistics (Tmogroup, 2015). It is a common trend in modern e-commerce business, especially for small and medium enterprises (SMEs), because it can reduce trade barriers and promote trade growth in an otherwise limited marketplace (Terzi, 2011). Sellers, manufacturers, and all participants of CBEC can profit from CBEC due to the large product assortment with low costs; this includes, perhaps especially, buyers (Kim et al., 2017). There are several studies focusing on the factors of CBEC success. For example, cross-border payments (Ai, Yang, \& Wang, 2016), logistic infrastructure and development (Cho \& Lee, 2017), and cultural adaption (Sinkovics, Mo, \& Hossinger, 2007) have each been investigated as imperative factors of CBEC success. Huang and Chang (2017) also illustrated the factors that affect consumers' intention to purchase items behind the perspective of perceived trust and value aspects. In addition, Guo et al. (2018) demonstrated that sellers' trust in buyers and perceived risk of chargeback fraud are also crucial to the success of CBEC. Meanwhile, it is important to note there are known risks posed to buyers, such as information asymmetry, private information misuse, and other uncertainty related to transactions and products (Mou, Cohen, Dou, \& Zhang, 2017).

CBEC in China has become the major way of foreign trade with growth rate of sixteen times that comparing to general trade. The main mode is B2B e-commerce, which accounts for $88 \%$ of all CBEC (Xue, Li, \& Pei, 2016). Moreover, the Chinese CBEC retail exports account for $37 \%$ of the global market share, which may be caused by two major manufacturing capacity advantages. First is China's advantage of being a "world factory"1 and second, the transformation in recent years to "create in China" rather than "made in China." These achievements attribute to the supportive policy of China such as "internet +" (Wang, Zhang, \& Sun, 2017) and "the Belt and Road Initiative project" (Li \& Chan, 2016). Despite this general success, many cross-border e-marketplaces have failed in recent years due to poor performance (Thitimajshima, Esichaikul, \& Krairit, 2018). For example, Metao.com, founded in 2013, quickly went bankrupt by 2016. It can be argued that Metao.com did not understand its own marketplace, hence its demise. Therefore, it is important to study CBEC to understand why it succeeds and why it might not, in order to drive more directly toward success.

\section{The Relationship Between Trust and Repurchase Intention}

Trust is formed by indicators from various formations, including trust feature signals, symbols, or cues provided by trustees (Mou \& Shin, 2018). It can also be referred to as the willingness of one to be vulnerable to the actions of another (Mayer, Davis, \& Schoorman, 1995). In a physical store, trust is generally built by the salesperson and the appearance of the store (Doney \& Cannon, 1997). Circumstances change when the store is online. Without the physical entity of the store itself, uncertainty increases. Customers cannot feel the "store" by senses directly, and the antecedents of trust are replaced by both perceived website quality and trust-related statements provided by e-vendors or platforms (Kraemer et al., 2005). Because trust can help to reduce fears and worries (Lu, Yang, Chau, \& Cao, 2011), it is crucial in the uncertain setting of CBEC (Kim et al., 2017). Naturally, the best trust is high and steady. Thus, CBEC platforms must assert their website quality is maximized, e-vendor and platform statements clean, and both consistently monitored for anything that could be perceived as negative or risky from the buyer perspective.

Empirical evidence suggests that trust directly influences the purchase intention of online customers (Kraemer et al., 2005; Mou, Shin, \& Cohen, 2017). For B-buyers, the transactions are always more frequent and in large scale, which facilitates the formation of long-term relationships with vendors. Thus, in this relationship between B-buyer and vendor, trust and commitment together will maintain cooperation and encourage an organic and loyal relationship (Li, Browne, \& Wetherbe, 2006). Moreover, the theory of reasoned action, which suggests that individual's beliefs influence 
behavior intention, naturally provides a foundation for the relationship between trust beliefs and intention behavior (Fishbein \& Ajzen, 1975). In this study, the authors classify trust as both that in the provider and in the website. Trust in the provider can enhance the relationship between B-buyers with a specific vendor, whereas CBEC website may reliable and own the functionality that the buyers needed, and therefore promote repurchase intention. Thus, the authors hypothesis that:

H1: Trust in provider positively affects repurchase intention.

$\mathrm{H} 2$ : Trust in website positively affects repurchase intention.

\section{The Relationship Between Perceived Risk and Repurchase Intention}

Perceived risk describes the customers' behavioral tendency of reducing and minimizing any expected negative effects associated with purchase activity (Peter \& Tarpey, 1975). It has been considered a major barrier for online consumers to make an online transaction. Various types of risk in market research have been identified, including, but not limited to financial, time, performance, physical, social, and psychological, (Tandon, Kiran, \& Sah, 2018; Marriott \& Williams, 2018). Financial risk refers to any monetary loss through technical or marketing channels, such as system error caused multiple purchase, sellers' fraud behavior, or return barriers. This monetary loss may include opportunity cost, time, or both. (Bhatnagar, Misra, \& Rao, 2000). When a customer decides to purchase online, a high perceived risk may influence him or her to cease the transaction, or even to be reluctant to shop in the first place (Antony, Lin, \& Xu, 2006). This risk does not exist in a traditional brick-and-mortar retail store (e.g. Tesco, Walmart), where customers can easily access the product they want, and touch, feel, even try the product before they make their decision. Indeed, as the distance between buyers and products decreases, so does the perceived risk (Kraemer et al., 2005).

Despite the varying distance between domestic and international e-commerce, product risk is generally the same in both situations. However, CBEC faces more challenges in the process of transactions. First, customs duties and taxes are one of the most distinct and major barriers in CBEC (Turban et al., 2017). Because B-buyers commonly order products in a large volume and more frequently, these barriers are more relevant for B2B customers. These costs may also include taxes coming from the buyer's own country. Meanwhile, it is important to note that products in large quantity are often subject to specific customs checks (Sinkovics et al., 2007), which leads to the second point: confiscation risk may occur due to either the vulnerability of cross-border transactions or problems related to potential shipping and customs, namely for products in large quantity. Further, the greater the distance, the more delivery time is implied the probability of loss or damage increases. Therefore, delivery risk is more serious in CBEC than domestic e-commerce. In addition, large-scale B2B transactions in CBEC must be aware of exchange rate fluctuations (apart from the financial risks which appear in domestic e-commerce). In fact, exchange rate fluctuation is the main potential risk.

Prior studies of e-commerce already show that perceived risk negatively affects a consumer's intention to purchase (Kraemer et al., 2005; Kuan \& Bock, 2007), but the authors believe this relationship will be amplified in CBEC, especially for $\mathrm{B} 2 \mathrm{~B}$, and there is more to be said on the subject. Thus, the following hypothesis has been proposed:

H3: Perceived risk negatively affects a consumer's intention to repurchase online.

\section{The Relationship Between Perceived Risk and Trust}

According to the extended valence framework (Kraemer et al., 2005), the net valence generated by perceived benefit and perceived risk is crucial during the process of making a purchase decision. As described above, perceived risk is the main barrier in CBEC. Therefore, when the uncertainty or risk appears, there must be a complement to neutralize the risk: trust is that complement (Kim, Ferrin, \& Rao, 2009). New research supplements that which has shown the negative effects of trust 
on perceived risk in e-commerce. This research suggests trust could be an antecedent of risk, the same as risk, or a by-product of risk - but all in all, they are different concepts (Kraemer et al., 2005). As described by Mayer et al. (1995), trust is constituted by three characteristics: ability, benevolence, and integrity. Ability is defined as the competence or beliefs that someone is capable of doing what is expected (Hallikainen \& Laukkanen, 2018). Benevolence refers to the belief that a trustee wants to do good to the trustor, aside from an egocentric profit motive (Mayer et al., 1995; Hong, 2018). Integrity refers to the belief that a company will act in a consistent, reliable, and honest manner when fulfilling its promises (Hong, 2018). Collectively, Hallikainen, Laukkanen, and Hong assert that if a trustor perceives a trustee with enough of these key characteristics, trust will be developed. Therefore, consumers would like to engage in a risky relationship with a vender if and only if the trust exceeds the threshold of perceived risk. In other words, trust has an inverse relationship with perceived risk. However, this studies show that the function of trust in affecting behavior intention (e.g. repurchase) is the same as risk, and their effect mechanisms are, to some degree, a reciprocal. In mobile commerce context (Lin, Wang, Wang, \& Lu, 2014), perceived risk can be reduced by pre-trust, and have a function of decreasing post-trust. Further, in an online environment, empirical evidence shows that risk perceptions can negatively influence multi-dimensional trust (Treiblmaier \& Chong, 2011). Therefore, if B-buyers in CBEC perceived lower risk either from vendors or the CBEC platform website, they will reduce their worry and fears, and become more risk tolerant. This makes sense, considering they trust their suppliers. Thus, the authors hypothesis that:

H4: Perceived risk negatively affects buyers' trust in providers.

H5: Perceived risk negatively affects buyers' trust in CBEC websites.

\section{The Relationship Between Alternative Website Quality and Trust}

Among numerous CBEC platforms, buyers can easily switch their choice through a single click. According to the information system success model (DeLone \& McLean, 2003), the quality of an information system is constituted by system quality, information quality, and service quality. In the context of this study, the authors refer to alternative website quality as the product quality and price buyers perceive of other CBEC platforms. Alternative quality is identified as a key factor to form and stabilize cooperative relationships (McKnight, Choudhury, \& Kacmar, 2002). If consumer needs can be better satisfied by another CBEC platform, the commitment of the current relationship will be reduced and easily replaced. Conversely, if consumers face poor, unstable, unsuitable alternatives or even just not as good as the current, they are more likely to stay firmly within the present relationship. Empirical evidence has shown that the quality of outcome available from the best alternative relationship partner can help to maintain a buyer-seller relationship in the context of B2B (Anderson \& Narus, 1990). In practice, if buyers find another, better CBEC platform website, they tend to devalue the old one and become reluctant to maintain the relationship (Johnson \& Rusbult, 1989). Therefore, it may reduce the trust of the current website along with their provider. Thus, the authors hypothesis the following:

H6: Alternative website quality negatively affects buyers' trust in providers.

H7: Alternative website quality negatively affects buyers' trust in CBEC websites.

\section{The Relationship Between Alternative Website Quality and Risk}

There are many aspects associated with alternative website quality. Other than the IS qualities discussed earlier, other factors also revolve around alternative quality, including payment protection mechanism, security and privacy protection, and positive reputation. Kim et al. (2008) has demonstrated that these elements of an e-commerce website can decrease (or increase) perceived risks from buyers and increase (or decrease) their trust. In the context of CBEC, consumers feel more uncertainty and risk due to the "long distance" (Kim et al., 2017) across borders and around the globe. Therefore, a high 
quality of a CBEC platform can reduce risk perception for consumers and make them less sensitive to uncertainty. Thus, the authors hypothesis that:

H8: Alternative website quality positively affects perceived risks from buyers.

\section{Trust Transfer Theory}

Trust transfer theory refers to the phenomenon that a trustor bases his or her original trust in a source, on the trust already embedded in another related target, or the same target in another context (Stewart, 2003). Generally, there are two types of relationships between source and target: similarity and business tie, respectively. A similarity relationship is regarded as an internal connection, and such a connection refers to the same features or attributes of trusted source and target. If two objects (i.e. source and target) have several traits in common, they will be perceived as belonging to the same category, and the trust transfer occurs. A business tie relationship represents external connection, which is displayed as a cue from outside sources. For example, if two products are from the same company, the two websites share interlinks. Trust transfer theory is important in understanding the mechanism of trust building, especially for related targets (Mou \& Cohen, 2017). If a customer trusts a salesman, then the customer likely trusts the products he or she sells, as well as the company he or she belongs to (Doney \& Cannon, 1997). Trust can also be transferred from brick and mortar retailers to their online shop (Kuan \& Bock, 2007). This is also a business tie relationship. To demonstrate similarity examples, the trust from internet payments can be transferred to mobile payments (Lu et al., 2011), and from internet and administration to public e-service (Belanche, Casaló, Flavián, \& Schepers, 2014).

In this study, the relationship between CBEC platform websites and its providers (sellers) is similar to the relationship between a company and its salesmen. As discussed above, this relationship belongs to business ties, because the CBEC platform does not have the similar features as website providers, albeit they are all bundled together. Therefore, the authors hypothesis the following:

H9: Trust in the CBEC platform website positively affect buyers' trust in providers.

\section{Control Variables}

National culture refers to the similar pattern of mental mode within a group of people (Hofstede, 1998). It has been shown to influence consumer behaviors (Thitimajshima et al., 2018). Culture differs from country to country, as well as among different locations within a single country. Researchers have applied culture to study different aspects of global information management, such as IT development, operations, management and use (Gallupe \& Tan, 1999). Consequently, CBEC is culture-bound. Because of this, culture is a control variable in this study.

In addition to culture, this study also includes age, gender, and income as control variables. Psychologists believe that demographics play an important role in an individual perceptual and judgment formation process. For example, researchers argue that gender differences are instrumental in consumer decision making process for online shopping context (Stafford, Turan, \& Raisinghani, 2004). Previously, researchers have found that males are more likely to use the Internet than females. Specifically, men are more likely than women to participate in online auctions and pay to download digital content (Sebastianelli, Tamimi, \& Rajan, 2008). In an online shopping context, younger and female consumers are more likely to impulsively purchase online, while older and male consumers are not (Leong, Jaafar, \& Ainin, 2018). Further, previous literatures also suggest that online consumer's age, gender and income may affect the intention to repurchase online (Aladwani, 2018; Farivar, Turel, $\&$ Yuan, 2018). On the other hand, buyers may be more sensitive to online transactions, or overly careful to when purchasing on CBEC due to uncertainties such as fraud. Therefore, the authors use fraud as another control variable. 
The research model is illustrated in Figure 1 below.

\section{RESEARCH METHODOLOGY}

\section{Research Setting}

To obtain a set of high-quality data, the authors collaborated with one of the biggest CBEC platforms in China, Dhgate.com. This firm is a wholesale market which delegates to help SMEs engage in global marketplaces through CBEC channels. It covers 1.2 million Chinese vendors with more than 30 million products, including, but not limited to the following: apparel \& accessories, computers \& networking, consumer electronics, toys $\&$ hobbies, health $\&$ beauty, bags $\&$ jewelry. On the buyer side, there are approximately 10 million enterprises and individual buyers from 220 countries and regions. In addition, to facilitate the consumers' purchase in this cross-border firm more easily, it runs both a PC-based website platform and a mobile/tablet-based application. To better collect target data, the authors distributed the survey through an online survey system.

\section{Measures}

In this paper, most items in surveys such as privacy risk, trust in vendor, trust in website and repeat purchase intention were adopted from previous literature, with small changes appropriate to the CBEC context. Some measures for confiscation risk, customs duties cost, and financial risk had to be developed based on input from industry experts and the conceptual definitions of those constructs. This was because existing measurement scales were not considered appropriate for the complex nature of CBEC compared to a domestic e-commerce setting. For example, confiscation risk was measured through four items reflecting the consumer's concern that customs authorities may intercept and confiscate their product without compensation. The authors measured customs duties cost refracting the uncertainty surrounding payment in additional import duties. The authors adopted five items from (Li et al., 2006) to measure alternative website quality, which reflect that an alternative website is attractive and appealing. The measurement items are present in Appendix B. The authors adopted the five-point Likert-scale, with anchors ranging from "strongly disagree," to "strongly agree."

\section{Data Collection}

The authors first conducted a pilot test to determine whether the survey instruments were understandable for participants and whether there are any ambiguous or confusing measurement items

\section{Figure 1. Research model}

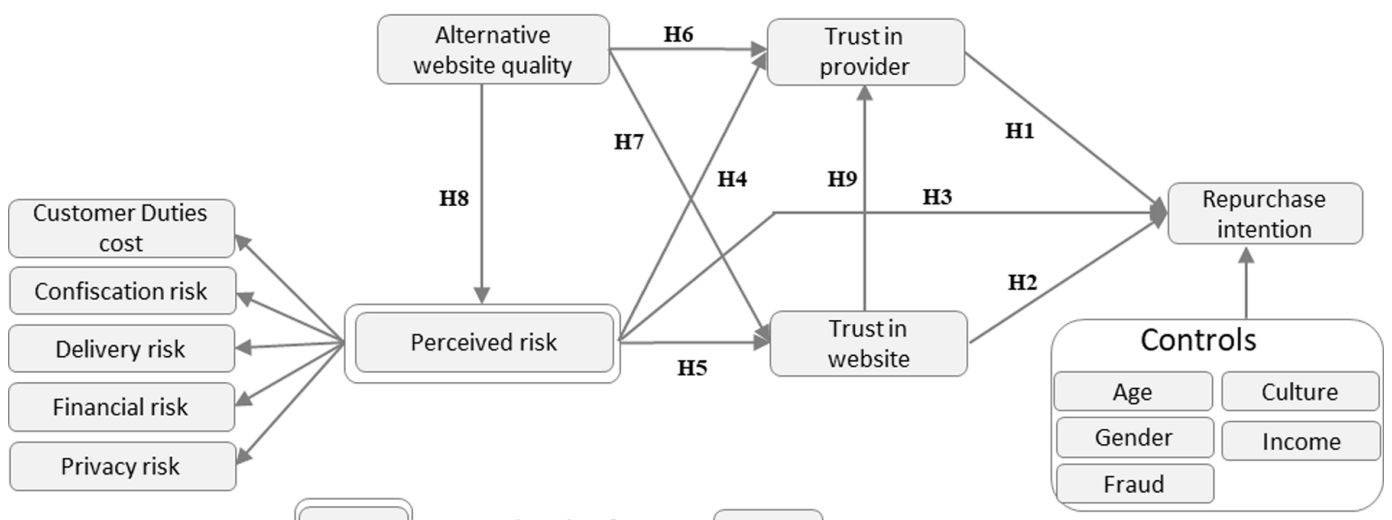


in the questionnaires, as well as to ensure that the survey items are appropriate in the CBEC context. To prevent poor response due to over-sampling, the random selection was limited to three out of every 100 site visitors (3\%) who had not participated in the provider's satisfaction survey within the previous three-month period. Based on the site's rules and to minimize disruption to their customers' shopping experience, the pop-up rate was decreased with approximately 12 respondents per day over a one-and-a-half-month period. Participating in the survey was totally voluntary, and anonymity was ensured by configuring the survey application to disregard any respondent identification information. When invited to consider participating, buyers could select to "participate now", "maybe next time", or "don't ask again". There was no loss of benefit whether or not a respondent chose to participate. The survey of this study was originally compiled in English.

Given the active visitors/users are different every day, the firm did not let us to know how many times in total the pop ups occurred during the sample period. The authors do know that during the weekdays, more samples were collected, while during weekend, less samples were available. Due to the voluntary trait of all participants, the authors believe that the individuals who took part in the activity were sufficiently random, and the sample was therefore not exhibited bias.

\section{RESULTS}

\section{Characteristics of Demographics}

After 6 weeks, the authors had obtained both C-buyer and B-buyer samples. To focus on B-buyers repurchase intention, the authors dropped responses from C-buyers. The authors ultimately adopted 243 B-buyer samples in total to test the research model. Demographic statistics are shown in Table 1, below. All participants in this study indicated that they had purchased products from an alternative Chinese cross-border website during last several months. As shown, most B-buyers were males (76.5\%). Furthermore, most of the respondents were of the age range between 21-50, regardless of gender. Among the respondents, a desirable majority of $88.5 \%$ had previous purchase experience in this cross-border website. In addition, the authors found that $37 \%$ were from the US, $7.4 \%$ from Canada, 7.4\% from the UK, 4.1\% from Australia, and 3.7\% from Brazil; others were mainly from other European countries such as Netherlands, Germany, Italy, Spain and other South America countries such as Chile. This greater proportion of responses from North America was not unexpected and is consistent with this firm's marketing strategies, which is largely focused on North America, Europe and English-speaking counties. Last, the test of common method bias, reliability, and validity can be found in Appendix C and D.

\section{Hypothesis Testing}

The structural model of this study was tested by using SmartPLS software. The authors used the bootstrap method (5,000 re-samples) to determine the significance of the paths in the research model. The PLS-SEM has been employed in this study due to the following reasons: first, it can estimate the items loadings of constructs and simultaneously test the relationship among the variables in which the authors are interested; second, it is appropriate for the small simple size. According to Chin and Newsted (1999), the sample size should be ten times the largest number of independent variables. This study has 13 independent variables (including control variables), and the sample size of 243 exceeds ten times that amount, therefore it is adequate for PLS-SEM analysis.

The constructs of alternative website quality, trust in provider, trust in website and repurchase intention were modeled as first order constructs. The authors model perceived risk as a second order construct. For the assessment of psychological constructs, researchers normally adopted either reflective measurement or formative measurement (Christophersen \& Konradt, 2012). In other words, many construct allow both reflective and formative measurement if the approach can be explained by an underlying theory (Chin, 1998). In this study, the authors considered perceived 
Table 1. Descriptive statistics of respondents' characteristics

\begin{tabular}{|c|c|c|c|}
\hline Demographics & Category & $N(n=243)$ & Percentage $(\%)$ \\
\hline \multirow{3}{*}{ Gender } & Male & 186 & $76.5 \%$ \\
\hline & Female & 54 & $22.2 \%$ \\
\hline & Missing & 3 & $1.3 \%$ \\
\hline \multirow{7}{*}{ Age } & Under 21 & 16 & $6.6 \%$ \\
\hline & $21-30$ & 56 & $23.0 \%$ \\
\hline & $31-40$ & 65 & $26.8 \%$ \\
\hline & $41-50$ & 51 & $21.0 \%$ \\
\hline & $51-60$ & 36 & $14.8 \%$ \\
\hline & Over 60 & 17 & $7.0 \%$ \\
\hline & Missing & 2 & $0.8 \%$ \\
\hline \multirow{11}{*}{ Country } & USA & 90 & $37.0 \%$ \\
\hline & Canada & 18 & $7.4 \%$ \\
\hline & UK & 18 & $7.4 \%$ \\
\hline & Australia & 10 & $4.1 \%$ \\
\hline & Brazil & 9 & $3.7 \%$ \\
\hline & Italy & 8 & $3.3 \%$ \\
\hline & Mexico & 6 & $2.5 \%$ \\
\hline & New Zealand & 5 & $2.1 \%$ \\
\hline & South Africa & 5 & $2.1 \%$ \\
\hline & Others & 69 & $28.4 \%$ \\
\hline & Missing & 5 & $2.0 \%$ \\
\hline \multirow{3}{*}{ This cross-border website purchase experience } & Yes & 215 & $88.5 \%$ \\
\hline & No & 27 & $11.2 \%$ \\
\hline & Missing & 1 & $0.4 \%$ \\
\hline
\end{tabular}

risk as a high-order reflective construct. This is because based on the approach of Featherman and Pavlou (2003), risk perceptions could be modeled as a reflective measurement construct. Secondly, reflective measurements are expected high correlation among first order construct e.g., customer duties cost, confiscation risk, delivery risk, financial risk and privacy risk. Further, the first order constructs can be interpreted as a criterion for high internal consistency (Christophersen \& Konradt, 2012). Therefore, all the constructs in this study are modeled as reflective factors. Further, the interassociations are considered to better understand the repurchase intention of CBEC.

As shown in Table 2, alternative website quality did not significantly influence trust in provider, nor trust in website. However, the authors found that alternative website quality can mediate perceived risk and thus indirectly influence trust in website. In addition, the authors found that perceived risk did not significantly influence trust in provider. Therefore, the path coefficients of H4, H6, and H7 were not significant. Further, the authors found that B-buyer repurchase intention is determined by trust in provider, trust in website and risk perceptions. Moreover, the authors found trust in website significantly influences trust in provider. Last, the authors found trust in website was significantly influenced by perceived risk. The authors therefore confirmed other hypothesis. No control variables 
were significant in this study. The research model explained 53.3 percent of the variance in repurchase intention of B-buyers to use this CBEC platform. In addition, according to Henseler et al. (2014), the authors applied the standardized root mean square residual (SRMR) as an index to evaluate the overall model fit. The value of SRMR is 0.054 , which is below the criteria value of 0.080 , indicating a good model fit. The results of the hypothesis test are depicted in Figure 2.

\section{Post-hoc Analysis of Mediating Effects}

The mediating effect of perceived risk on the path between alternative website quality and perceived risk, the mediating effect of trust in website on the link between perceived risk and trust in provider have also been carried out via a Sobel test. The Sobel test allows us to test the mediating effects suggested by the research model. The authors found that perceived risk plays a full mediation effect on the path between alternative website quality and perceived risk $(-2.075, \mathrm{p}<0.05)$. In addition, support for trust in website as a fully explanatory variable for the effects of perceived risk on trust in provider is confirmed by a significant Sobel statistic $(-2.908, \mathrm{p}<0.01)$.

Figure 2. PLS test of research model (dash line represents non-significant results)

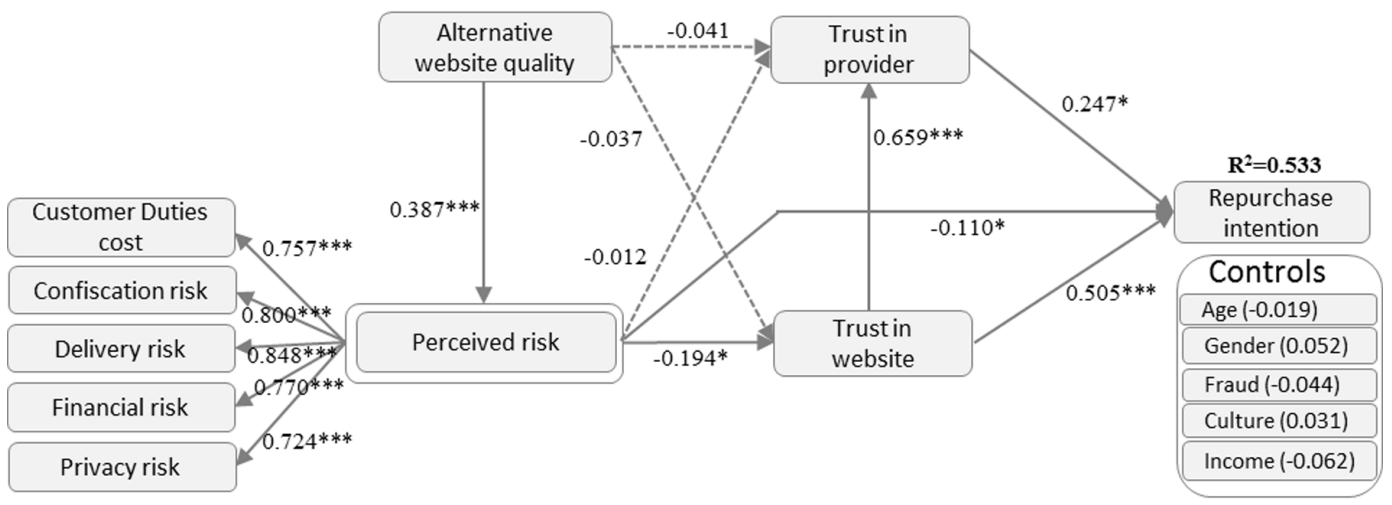

Table 2. Summary of results ( $\left.{ }^{*} p<0.05 ;{ }^{* *} p<0.001\right)$.

\begin{tabular}{|l|l|l|l|}
\hline \multicolumn{1}{|c|}{ Hypothesis (path) } & \multicolumn{1}{|c|}{ Path coefficient } & \multicolumn{1}{c|}{ t-Value } & \multicolumn{1}{c|}{ Support } \\
\hline H1 & 0.247 & $2.546^{*}$ & Yes \\
\hline H2 & 0.505 & $5.111^{* * *}$ & Yes \\
\hline H3 & -0.110 & $2.328^{*}$ & Yes \\
\hline H4 & -0.012 & 0.190 & No \\
\hline H5 & -0.194 & $2.103^{*}$ & Yes \\
\hline H6 & -0.041 & 0.648 & No \\
\hline H7 & -0.037 & 0.398 & No \\
\hline H8 & 0.387 & $6.021^{* * *}$ & Yes \\
\hline H9 & 0.659 & $10.778^{* * *}$ & Yes \\
\hline
\end{tabular}




\section{Discussion}

In this day and age, CBEC and global trade go hand in hand. While B-buyers can contribute more margin for the firm, they also contribute more GMV in a CBEC platforms. There are some studies that focus on B-buyer behaviors in domestic online shopping, which can help scholars to gain more insight in studding e-commerce. However, through reviewing the CBEC literature, there still remains a lack of studies to investigate B-buyer behavior under CBEC context. Therefore, the authors apply trust transfer theory, perceived risk, and alternative website quality to study repurchase intention focusing on B-buyers.

The authors found that perceived risk can negatively affect the trust in website, whereas it cannot significantly affect trust in the provider. This is because providers in the CBEC website were generally SMEs, which were not influential in the website. As a result, consumer's perception, trust, and behavior intention were more relied on the website rather than the provider. This could also explain why trust in website could influence trust in provider, and why the path coefficient between trust in website and repurchase intention was larger than that of the trust in provider.

Further, trust in provider, trust in website and perceived risk can explain 53.3\% variance. This is slightly higher than the study of (Thatcher et al., 2013), whom found that trust in merchant, trust in website, and trust propensity can explain $51.1 \%$ of the variance for familiar shopping buyers, however such factors only explain $34.1 \%$ variance for new buyers. In an CBEC environment, the whole transaction processes such as surfing, querying, ordering, and payment are achieved via website. A trusted website is more likely to form consumer's positive purchase behaviors, while in a virtual environment, sellers and buyers only can interactive through website, as they normally do not know each other well. Indeed, only based on the perceptions of seller's website can the consumers make an initial decision for their purchase. Therefore, trust in website becomes more important than trust in provider in the context of CBEC.

The authors found that trust in website can significantly influence trust in provider $(\beta=0.659)$. This finding can answer the second question of this study. The effect between the link is higher than the study of (Vakeel et al., 2017), who only found the effect as 0.364 in consumer post purchase stage in a domestic setting. This is constant with trust transfer theory, which states that trust may transfer from different kinds of sources. Trust transfer theory has been studied under the context of e-commerce, mobile commerce, as well as social commerce. As an extension, this study found that trust in website can also influence trust in provider in CBEC environment.

Interestingly, alternative website quality did not affect the trust in either the provider or the website. When a consumer perceives an alternative CBEC website as a high quality, she/he is more likely to form positive perceptions for alternatives. Consumers are more easily to compare both websites. Since the consumers consider the alternatives are much better, the risk perceptions of this website may arise. Obviously, alternative website quality could indirectly influence repurchase intention. Thus, from the result of this study the authors could deduce that alternative website quality affects repurchase intention through mechanisms other than trust. In the current study, the authors confirmed that perceived risk mediated the link between alternative website quality and behavior intention. The authors believe there are also other mediators which may play an important role between alternative website quality and trust. This easily is one further research topic.

Thus far, we identified the dimensions of risk in CBEC environment to namely include customer duties cost risk, confiscation risk, delivery risk, financial risk and privacy risk. Multi-dimensional risk is also seen relevant, and given the complex transaction nature of CBEC, the authors found customer duties cost risk and confiscation risk are important as well.

\section{THEORETICAL CONTRIBUTIONS}

Theoretically, the authors have first classified the perceived risks as customer duties cost, confiscation risk, deliver risk, financial risk, and privacy risk. This is different with prior studies, which classified 
the dimensions of risk perceptions as financial risk, performance risk, delivery risk, psychological risk, social risk, time risk, and privacy risk (Featherman \& Pavlou, 2003). This can help researchers to better understand the dimensions of risk perception in CBEC context. Second, the authors found that the trust in website can positively affect the trust in provider, as well as affect the repurchase intention. This helps to solidify the trust transfer theory in CBEC context. Third, we found that alternative website quality indirectly influences consumer trust. Prior studies have confirmed the direct effect of website quality on trust. Meanwhile, alternative website quality is not a function of both trust in provider and trust in website in the context of CBEC.

\section{PRACTICAL CONTRIBUTIONS}

Practically speaking, this study first contributed to understanding perceived risk for B-buyers in CBEC environments. It can help any CBEC website to attract more consumers by developing their own security guarantee and compensation mechanism due to logistic issues, since these are the most influential perceived risks. For example, a buyer suggests that "the sellers should try their best to reduce the risk of custom duties, to improve buyer's purchase intention on a CBEC platform". Another buyer leaved a comment, “... often overpriced duty charges". One buyer complained about "a custom duty of $\$ 345$ on my recent order". Another notable comment by a buyer suggested to "reduce shipping cost a bit because customs duty this side is costly". The CBEC platform may satisfy the consumers by indicating the information about duty costs. Given that all the transactions are international, studying the term of custom duty cost is important to help CBEC platforms and logistic service firms build their appropriate service strategy. Confiscation risk has also been a concern for buyers. For instance, a buyer mentioned, "Sellers should announce the buyer if the item is lost or hold by China custom as soon as they know about it."

Secondly, increasing trust in website can promote significant repurchase intention, thereby increasing the quality of website. Thus, increasing website trust is imperative. This can guide CBEC firms to build an appropriate marketing strategy. For example, by mitigating risk perceptions, CBEC firms may strongly improve consumer trust and as a result, improve B-buyers' repurchase behavior. The degree of trust in provider can also drive consumers' behavior. Sellers should provide a good product description in their online shop.

In CBEC context, products with description related issues are frequently reported. For example, a buyer posted, "the product descriptions are often poorly written. When I come across a product description with poor grammar, typos, etc. I tend to skip over it because it makes me afraid that the product may be flawed as well'. In addition, another buyer complained of receiving products that did not meet expectations, on multiple occasions. This buyer followed the complaint with the suggestion that "sellers should ensure that their description is accurate." CBEC sellers should translate appropriate language to overcome the language barriers. This can help buyers to better understand the products, and therefore help the buyers form positive repurchase behaviors. CBEC platforms should build rules to regulate seller's behavior, lead seller providing high quality products, and therefore gain more trust form buyers. For instance, the platform can set up more parameters when the seller is uploading a product. If and only if the product meets its criterion, it may be published online.

Last, the authors found risk perceptions are negatively associated with repurchase intentions. The firms should disclose the duty cost, deliver only the products under regulations, deliver the products in a timely manner, and do not disclose consumer's private information to any third parties. This will potentially decrease the buyers' risk perceptions, and therefore lead more sales. 


\section{LIMITATIONS AND FUTURE RESEARCH}

This study has some limitations. First, the authors chose a single CBEC platform to collect the sample, which may potentially threat generalizability. Future research may collect data from several CBEC platforms. Second, the data was cross-sectional, and therefore, causal inferences could only be made with reference to theory. Future studies may adopt longitudinal designs and consider the temporal changes in human beliefs toward CBEC context. Finally, unexplored factors may be also important for CBEC; this is another further research point.

\section{ACKNOWLEDGMENT}

We would like to thank the editor and the anonymous reviewers and Dr. Jason Cohen for their comments, which have greatly improved our paper. This study supported by the Fundamental Research Funds for the Central Universities of No. 20103176477 [BX180604]. 


\section{REFERENCES}

Ai, W., Yang, J., \& Wang, L. (2016). Revelation of cross-border logistics performance for the manufacturing industry development. International Journal of Mobile Communications, 14(6), 593-609. doi:10.1504/ IJMC.2016.079302

Aladwani, A. M. (2018). A quality-facilitated socialization model of social commerce decisions. International Journal of Information Management, 40, 1-7. doi:10.1016/j.ijinfomgt.2018.01.006

Anderson, J. C., \& Narus, J. A. (1990). A model of distributor firm and manufacturer firm working partnerships. Journal of Marketing, 54(1), 42-58. doi:10.1177/002224299005400103

Antony, S., Lin, Z., \& Xu, B. (2006). Determinants of escrow service adoption in consumer-to-consumer online auction market: An experimental study. Decision Support Systems, 42(3), 1889-1900. doi:10.1016/j. dss.2006.04.012

Belanche, D., Casaló, L. V., Flavián, C., \& Schepers, J. (2014). Trust transfer in the continued usage of public e-services. Information \& Management, 51(6), 627-640. doi:10.1016/j.im.2014.05.016

Bhatnagar, A., Misra, S., \& Rao, H. R. (2000). On risk, convenience, and internet shopping behavior. Communications of the ACM, 43(11), 98-105. doi:10.1145/353360.353371

Chin, W. W. (1998). The partial least squares approach for structural equation modeling. In G. A. Marcoulides (Ed.), Modern methods for business research (pp. 295-336). Hillsdale, IN: Lawrence Erlbaum Associates.

Chin, W. W., \& Newsted, P. R. (1999). Structural equation modeling analysis with small samples using partial least squares. In R. H. Hoyle (Ed.), Statistical strategies for small sample research (pp. 307-342). Thousand Oaks, CA: Sage.

Chiu, C. M., Wang, E. T. G., Fang, Y. H., \& Huang, H. Y. (2014). Understanding customers' repeat purchase intentions in b2c e-commerce: The roles of utilitarian value, hedonic value and perceived risk. Information Systems Journal, 24(1), 85-114. doi:10.1111/j.1365-2575.2012.00407.x

Cho, H., \& Lee, J. (2017). Searching for logistics and regulatory determinants affecting overseas direct purchase: An empirical cross-national study. Asian Journal of Shipping \& Logistics, 33(1), 11-18. doi:10.1016/j. ajs1.2017.03.002

Christophersen, T., \& Konradt, U. (2012). Development and validation of a formative and a reflective measure for the assessment of online store usability. Behaviour \& Information Technology, 31(9), 839-857. doi:10.108 0/0144929X.2010.529165

DeLone, W. H., \& McLean, E. R. (2003). The DeLone and McLean model of information systems success: A tenyear update. Journal of Management Information Systems, 19(4), 9-30. doi:10.1080/07421222.2003.11045748

Doney, P. M., \& Cannon, J. P. (1997). An examination of the nature of trust in buyer-seller relationships. Journal of Marketing, 61(2), 35-51.

Farivar, S., Turel, O., \& Yuan, Y. (2018). Skewing users' rational risk considerations in social commerce: An empirical examination of the role of social identification. Information \& Management, 55(8), 1038-1048. doi:10.1016/j.im.2018.05.008

Featherman, M. S., \& Pavlou, P. A. (2003). Predicting e-services adoption: A perceived risk facets perspective. International Journal of Human-Computer Studies, 59(4), 451-474. doi:10.1016/S1071-5819(03)00111-3

Fishbein, M., \& Ajzen, I. (1975). Belief, attitude, intention and behaviour: An introduction to theory and research. Philosophy \& Rhetoric, 41(4), 842-844.

Gallupe, R. B., \& Tan, F. B. (1999). A research manifesto for global information management. Journal of Global Information Management, 7(3), 5-18. doi:10.4018/jgim.1999070101

Gefen, D. (2002). Customer loyalty in e-commerce. Journal of the Association for Information Systems, 3(1), 27-51. doi:10.17705/1jais.00022

Gomez-Herrera, E., Martens, B., \& Turlea, G. (2014). The drivers and impediments for cross-border e-commerce in the EU. Information Economics and Policy, 28(1), 83-96. doi:10.1016/j.infoecopol.2014.05.002 
Guo, Y., Bao, Y., Stuart, B. J., \& Le-Nguyen, K. (2018). To sell or not to sell: Exploring sellers' trust and risk of chargeback fraud in cross-border electronic commerce. Information Systems Journal, 28(2), 359-383. doi:10.1111/isj.12144

Hallikainen, H., \& Laukkanen, T. (2018). National culture and consumer trust in e-commerce. International Journal of Information Management, 38(1), 97-106. doi:10.1016/j.ijinfomgt.2017.07.002

Henseler, J., Dijkstra, T. K., Sarstedt, M., Ringle, C. M., Diamantopoulos, A., Straub, D. W., \& Calantone, R. J. et al. (2014). Common beliefs and reality about PLS: Comments on Rönkkö and Evermann (2013). Organizational Research Methods, 17(2), 182-209. doi:10.1177/1094428114526928

Hofstede, G. (1998). Identifying organizational subcultures: An empirical approach. Journal of Management Studies, 35(1), 1-12. doi:10.1111/1467-6486.00081

Hong, I. B. (2018). Building Initial Trust in an Intermediary in B2C Online Marketplaces: The Korean Evidence from Interpark.com. Journal of Global Information Management, 26(2), 27-47. doi:10.4018/JGIM.2018040102

Hong, I. B., \& Cha, H. S. (2013). The mediating role of consumer trust in an online merchant in predicting purchase intention. International Journal of Information Management, 33(6), 927-939. doi:10.1016/j. ijinfomgt.2013.08.007

Huang, S. L., \& Chang, Y. C. (2017). Factors that impact consumers' intention to shop on foreign online stores. Proceedings of Hawaii International Conference on System Sciences.

iResearch. (2017). Report for online consumption in 2017. Retrieved from http://www.iresearch.cn/include/ajax/ user_ajax.ashx?work=idown\&rid $=3128$

Johnson, D. J., \& Rusbult, C. E. (1989). Resisting temptation: Devaluation of alternative partners as a means of maintaining commitment in close relationships. Journal of Personality and Social Psychology, 57(6), 967-980. doi:10.1037/0022-3514.57.6.967

Kalia, P., Arora, D. R., \& Kumalo, S. (2016). E-service quality, consumer satisfaction and future purchase intentions in e-retail. e-Service Journal, 10(1), 24-41. doi:10.2979/eservicej.10.1.02

Kim, D. J., Ferrin, D. L., \& Rao, H. R. (2008). A trust-based consumer decision-making model in electronic commerce: The role of trust, perceived risk, and their antecedents. Decision Support Systems, 44(2), 544-564. doi:10.1016/j.dss.2007.07.001

Kim, D. J., Ferrin, D. L., \& Rao, H. R. (2009). Trust and satisfaction, two stepping stones for successful e-commerce relationships: A longitudinal exploration. Information Systems Research, 20(2), 237-257. doi:10.1287/isre. 1080.0188

Kim, T. Y., Dekker, R., \& Heij, C. (2017). Cross-border electronic commerce: Distance effects and express delivery in European union markets. International Journal of Electronic Commerce, 21(2), 184-218. doi:10.1 080/10864415.2016.1234283

Kraemer, K. L., Gibbs, J., \& Dedrick, J. (2005). Impacts of globalization on e-commerce use and firm performance: A cross-country investigation. The Information Society, 21(5), 323-340. doi:10.1080/01972240500253350

Kuan, H. H., \& Bock, G. W. (2007). Trust transference in brick and click retailers: An investigation of the beforeonline-visit phase. Information \& Management, 44(2), 175-187. doi:10.1016/j.im.2006.12.002

Leong, L. Y., Jaafar, N. I., \& Ainin, S. (2018). The effects of Facebook browsing and usage intensity on impulse purchase in f-commerce. Computers in Human Behavior, 78, 160-173. doi:10.1016/j.chb.2017.09.033

Li, C., \& Chan, T. (2016). Ten China commercial highlights 2016 series: Cross-border e-commerce import businesses see rapid growth; new channels for commercial enterprises to transform and innovate. Retrieved from https://www.fbicgroup.com/sites/default/files/Ten\%20Highlights\%20of\%20China's\%20Commercial\%20 Sector\%202016_07.pdf

Li, D., Browne, G., \& Wetherbe, J. (2006). Why do internet users stick with a specific web site? A relationship perspective. International Journal of Electronic Commerce, 10(4), 105-141. doi:10.2753/JEC1086-4415100404

Lin, J., Wang, B., Wang, N., \& Lu, Y. (2014). Understanding the evolution of consumer trust in mobile commerce: A longitudinal study. Information Technology Management, 15(1), 37-49. doi:10.1007/s10799-013-0172-y 
Lu, Y., Yang, S., Chau, P. Y. K., \& Cao, Y. (2011). Dynamics between the trust transfer process and intention to use mobile payment services: A cross-environment perspective. Information \& Management, 48(8), $393-403$. doi:10.1016/j.im.2011.09.006

Marriott, H. R., \& Williams, M. D. (2018). Exploring consumers perceived risk and trust for mobile shopping: A theoretical framework and empirical study. Journal of Retailing and Consumer Services, 42, $133-146$. doi:10.1016/j.jretconser.2018.01.017

Mayer, R. C., Davis, J. H., \& Schoorman, F. D. (1995). An integrative model of organizational trust. Academy of Management Review, 20(3), 709-734. doi:10.5465/amr.1995.9508080335

McKnight, D. H., Choudhury, V., \& Kacmar, C. (2002). Developing and validating trust measures for e-commerce: An integrative typology. Information Systems Research, 13(3), 334-359. doi:10.1287/isre.13.3.334.81

Ministry of Commerce. (2017). Report of electronic commerce in China. Retrieved from http://images.mofcom. gov.cn/dzsws/201706/20170621110205702.pdf

Mou, J., \& Cohen, J. (2017). Trust and online consumer health service success: A longitudinal study. Information Development, 33(2), 169-189. doi:10.1177/0266666916642507

Mou, J., Cohen, Y., Dou, Y., \& Zhang, B. (2017). Predicting buyers' repurchase intentions in cross-border e-commerce: A valence framework perspective. Proceedings of the 25th European Conference on Information Systems.

Mou, J., \& Shin, D. (2018). Effects of social popularity and time scarcity on online consumer behavior regarding smart healthcare products: An eye-tracking approach. Computers in Human Behavior, 78, 74-89. doi:10.1016/j. chb.2017.08.049

Mou, J., Shin, D., \& Cohen, J. (2017). Understanding trust and perceived usefulness in the consumer acceptance of an e-service: A longitudinal investigation. Behaviour \& Information Technology, 36(2), 125-139. doi:10.1 080/0144929X.2016.1203024

Pavlou, P. A., Liang, H., \& Xue, Y. (2007). Understanding and mitigating uncertainty in online exchange relationships: A principal-agent perspective. Management Information Systems Quarterly, 31(1), $105-136$. doi: $10.2307 / 25148783$

Peter, J. P., \& Tarpey, L. X. Sr. (1975). A comparative analysis of three consumer decision strategies. The Journal of Consumer Research, 2(1), 29-37. doi:10.1086/208613

Podsakoff, P. M., \& Organ, D. W. (2016). Self-reports in organizational research: Problems and prospects. Journal of Management, 12(4), 531-544. doi:10.1177/014920638601200408

Rönkkö, M., \& Ylitalo, J. (2011). PLS marker variable approach to diagnosing and controlling for method variance. Proceedings of the International Conference on Information Systems.

Sebastianelli, R., Tamimi, N., \& Rajan, M. (2008). Perceived quality of online shopping: Does gender make a difference? Journal of Internet Commerce, 7(4), 445-469. doi:10.1080/15332860802507164

Sinkovics, R. R., Mo, Y., \& Hossinger, M. (2007). Cultural adaptation in cross border e-commerce: A study of German companies. Journal of Electronic Commerce Research, 8(4), 221-235.

Sørum, H. (2015). The role of quality in websites: A discussion focusing on public versus private sector organizations. Springer International Publishing Switzerland. doi:10.1007/978-3-319-21006-3_10

Stafford, T. F., Turan, A., \& Raisinghani, M. S. (2004). International and cross-cultural influences on online shopping behavior. Journal of Global Information Technology Management, 7(2), 70-87.

Stewart, K. J. (2003). Trust transfer on the world wide web. Organization Science, 14(1), 5-17.

Tandon, U., Kiran, R., \& Sah, A. N. (2018). The influence of website functionality, drivers and perceived risk on customer satisfaction in online shopping: An emerging economy case. Information Systems and e-Business Management, 16(1), 57-91. doi:10.1007/s10257-017-0341-3

Terzi, N. (2011). The impact of e-commerce on international trade and employment. Procedia: Social and Behavioral Sciences, 24, 745-753. doi:10.1016/j.sbspro.2011.09.010 
Thatcher, J. B., Carter, M., Li, X., \& Rong, G. (2013). A classification and investigation of trustees in B-to-C e-commerce: General vs. specific trust. Communications of the Association for Information Systems, 32(1), $107-134$.

Thitimajshima, W., Esichaikul, V., \& Krairit, D. (2018). A framework to identify factors affecting the performance of third-party B2B e-marketplaces: A seller's perspective. Electronic Markets, 28(2), 129-147. doi:10.1007/ s12525-017-0256-3

Tmogroup. (2015). Differences between cross border e-commerce \& Haitao. Retrieved from https://www. tmogroup.asia/difference-between-cross-border-ecommerce-haitao/

Treiblmaier, H., \& Chong, S. (2011). Trust and perceived risk of personal information as antecedents of online information disclosure: Results from three countries. Journal of Global Information Management, 19(4), 76-94. doi:10.4018/jgim.2011100104

Turban, E., Whiteside, J., King, D., \& Outland, J. (2017). Implementation issues: From globalization to justification, privacy, and regulation. In Introduction to Electronic Commerce and Social Commerce. Springer International Publishing. doi:10.1007/978-3-319-50091-1

Vakeel, K. A., Das, S., Udo, G. J., \& Bagchi, K. (2017). Do security and privacy policies in B2B and B2C e-commerce differ? A comparative study using content analysis. Behaviour \& Information Technology, 36(4), 390-403. doi:10.1080/0144929X.2016.1236837

Wang, X., Zhang, J., \& Sun, D. (2017). The “internet+” based study on the development strategy about SinoRussian cross-border e-commerce. Proceedings of the Fourth International Forum on Decision Sciences.

Wikipedia. (n.d.). Belt and Road Initiative. Retrieved from https://en.wikipedia.org/wiki/Belt_and_Road_Initiative Xue, W., Li, D., \& Pei, Y. (2016). The Development and Current of Cross-border E-commerce. Proceedings of Wuhan International Conference on Electronic Business.

\section{ENDNOTES}

Due to the industrial revolution and the data on China's manufacturing values added, China can produce a huge quantity of products, this leads a huge amount of merchandise exports. The authors therefore call it a "world factory."

2 The Belt and Road Initiative project is a development strategy adopted by the Chinese government. The 'belt' refers to the overland interconnecting infrastructure corridors. The 'road' refers to the sea route corridors. The initiative focuses on connectivity and cooperation between Eurasian countries and China (Wikipedia). 
APPENDIX A: CROSS-LOADING

Table 3. Cross-loading

\begin{tabular}{|c|c|c|c|c|c|c|c|c|c|}
\hline & AWQ & CD & CR & DR & FR & PC & RPI & TV & TW \\
\hline AWQ1 & 0.687 & 0.122 & 0.132 & \begin{tabular}{|l|}
0.121 \\
\end{tabular} & 0.144 & 0.142 & -0.066 & -0.006 & 0.026 \\
\hline AWQ2 & 0.896 & 0.273 & 0.232 & \begin{tabular}{|l|}
0.289 \\
\end{tabular} & 0.255 & 0.283 & -0.287 & -0.145 & -0.187 \\
\hline AWQ3 & 0.842 & 0.310 & 0.282 & \begin{tabular}{|l|}
0.368 \\
\end{tabular} & 0.311 & 0.338 & \begin{tabular}{|l|}
-0.171 \\
\end{tabular} & \begin{tabular}{|l|}
-0.075 \\
\end{tabular} & \begin{tabular}{|c|}
-0.084 \\
\end{tabular} \\
\hline AWQ4 & 0.854 & 0.249 & 0.230 & 0.246 & 0.228 & 0.230 & -0.175 & -0.010 & -0.018 \\
\hline AWQ5 & 0.859 & 0.228 & 0.196 & 0.224 & 0.241 & 0.268 & -0.266 & -0.200 & -0.120 \\
\hline CD1 & 0.271 & 0.973 & 0.590 & \begin{tabular}{|l|}
0.480 \\
\end{tabular} & 0.540 & 0.343 & -0.159 & -0.098 & -0.163 \\
\hline $\mathrm{CD} 2$ & 0.301 & 0.933 & 0.569 & \begin{tabular}{|l|}
0.457 \\
\end{tabular} & 0.532 & 0.367 & -0.102 & -0.091 & -0.099 \\
\hline CR1 & 0.180 & 0.580 & 0.895 & \begin{tabular}{|l|}
0.529 \\
\end{tabular} & 0.468 & 0.427 & \begin{tabular}{|l|}
-0.044 \\
\end{tabular} & \begin{tabular}{|l|}
-0.069 \\
\end{tabular} & \begin{tabular}{|l}
-0.026 \\
\end{tabular} \\
\hline CR2 & 0.200 & 0.568 & 0.904 & \begin{tabular}{|l|}
0.554 \\
\end{tabular} & 0.486 & 0.424 & \begin{tabular}{|l|}
-0.037 \\
\end{tabular} & \begin{tabular}{|l|}
-0.047 \\
\end{tabular} & -0.010 \\
\hline CR3 & 0.253 & 0.510 & 0.913 & \begin{tabular}{|l|}
0.534 \\
\end{tabular} & 0.453 & 0.451 & \begin{tabular}{|l|}
-0.071 \\
\end{tabular} & -0.046 & -0.032 \\
\hline CR4 & 0.268 & 0.592 & 0.966 & \begin{tabular}{|l|}
0.589 \\
\end{tabular} & 0.489 & 0.472 & \begin{tabular}{|l|}
-0.177 \\
\end{tabular} & -0.152 & -0.132 \\
\hline DR1 & 0.259 & 0.409 & 0.516 & \begin{tabular}{|l|}
0.857 \\
\end{tabular} & 0.458 & 0.443 & -0.273 & -0.125 & -0.239 \\
\hline DR2 & 0.280 & 0.364 & 0.495 & \begin{tabular}{|l|}
0.890 \\
\end{tabular} & 0.395 & 0.476 & -0.276 & -0.168 & -0.222 \\
\hline DR3 & 0.256 & 0.413 & 0.455 & \begin{tabular}{|l|}
0.877 \\
\end{tabular} & 0.453 & 0.408 & -0.332 & \begin{tabular}{|l|}
-0.232 \\
\end{tabular} & -0.281 \\
\hline DR4 & 0.265 & 0.450 & 0.583 & \begin{tabular}{|l|}
0.792 \\
\end{tabular} & 0.535 & 0.469 & -0.165 & -0.073 & -0.154 \\
\hline DR5 & 0.257 & 0.468 & 0.549 & \begin{tabular}{|l|}
0.780 \\
\end{tabular} & 0.475 & 0.516 & -0.239 & -0.210 & -0.121 \\
\hline FR1 & 0.282 & 0.526 & 0.478 & 0.515 & 0.995 & 0.407 & -0.166 & -0.118 & \begin{tabular}{|l}
-0.159 \\
\end{tabular} \\
\hline FR2 & 0.255 & 0.620 & 0.562 & \begin{tabular}{|l|}
0.530 \\
\end{tabular} & 0.716 & 0.408 & -0.024 & 0.007 & -0.120 \\
\hline PC1 & 0.323 & 0.377 & 0.481 & 0.506 & 0.440 & 0.931 & \begin{tabular}{|l|}
-0.199 \\
\end{tabular} & -0.117 & -0.144 \\
\hline $\mathrm{PC} 2$ & 0.281 & 0.311 & 0.443 & \begin{tabular}{|l|}
0.478 \\
\end{tabular} & 0.381 & 0.952 & \begin{tabular}{|l|}
-0.159 \\
\end{tabular} & -0.075 & -0.121 \\
\hline PC3 & 0.290 & 0.329 & 0.438 & \begin{tabular}{|l|}
0.484 \\
\end{tabular} & 0.375 & 0.955 & \begin{tabular}{|l|}
-0.172 \\
\end{tabular} & \begin{tabular}{|l|}
-0.105 \\
\end{tabular} & \begin{tabular}{|l|}
-0.140 \\
\end{tabular} \\
\hline PC4 & 0.291 & 0.351 & 0.425 & \begin{tabular}{|l|l|}
0.484 \\
\end{tabular} & 0.399 & 0.812 & -0.069 & -0.061 & -0.060 \\
\hline PC5 & 0.227 & 0.301 & 0.398 & \begin{tabular}{|l|}
0.520 \\
\end{tabular} & 0.313 & 0.823 & -0.107 & -0.039 & -0.062 \\
\hline RPI1 & -0.235 & -0.130 & -0.095 & -0.276 & -0.137 & -0.194 & \begin{tabular}{|l|}
0.912 \\
\end{tabular} & 0.526 & 0.622 \\
\hline RPI2 & -0.250 & -0.139 & -0.151 & -0.368 & -0.138 & -0.184 & \begin{tabular}{|l|}
0.876 \\
\end{tabular} & 0.545 & 0.618 \\
\hline RPI3 & \begin{tabular}{|l|}
-0.230 \\
\end{tabular} & \begin{tabular}{|l|}
-0.177 \\
\end{tabular} & -0.174 & \begin{tabular}{|l|}
-0.331 \\
\end{tabular} & -0.181 & -0.169 & \begin{tabular}{|l|}
0.938 \\
\end{tabular} & 0.574 & \begin{tabular}{|l|}
0.620 \\
\end{tabular} \\
\hline RPI4 & -0.243 & \begin{tabular}{|l|}
-0.123 \\
\end{tabular} & -0.107 & \begin{tabular}{|l|}
-0.259 \\
\end{tabular} & -0.134 & -0.133 & \begin{tabular}{|l|}
0.929 \\
\end{tabular} & 0.588 & \begin{tabular}{|l|}
0.646 \\
\end{tabular} \\
\hline RPI5 & -0.271 & \begin{tabular}{|l|}
-0.131 \\
\end{tabular} & -0.107 & -0.250 & -0.139 & -0.134 & \begin{tabular}{|l|}
0.942 \\
\end{tabular} & 0.583 & 0.628 \\
\hline RPI6 & -0.228 & -0.093 & -0.077 & -0.271 & -0.127 & -0.138 & \begin{tabular}{|l|l|}
0.932 \\
\end{tabular} & 0.550 & 0.672 \\
\hline TV1 & \begin{tabular}{|l|}
-0.147 \\
\end{tabular} & -0.074 & -0.062 & -0.197 & -0.128 & -0.069 & \begin{tabular}{|l|}
0.550 \\
\end{tabular} & 0.886 & 0.616 \\
\hline TV2 & \begin{tabular}{|l|}
-0.121 \\
\end{tabular} & \begin{tabular}{|l|}
-0.140 \\
\end{tabular} & -0.131 & \begin{tabular}{|l|}
-0.223 \\
\end{tabular} & -0.145 & -0.079 & \begin{tabular}{|l|}
0.536 \\
\end{tabular} & 0.909 & \begin{tabular}{|l|}
0.630 \\
\end{tabular} \\
\hline TV3 & \begin{tabular}{|l}
-0.105 \\
\end{tabular} & \begin{tabular}{|l|}
-0.045 \\
\end{tabular} & -0.063 & \begin{tabular}{|l|}
-0.192 \\
\end{tabular} & \begin{tabular}{|l|}
-0.072 \\
\end{tabular} & -0.111 & \begin{tabular}{|l|}
0.564 \\
\end{tabular} & 0.928 & \begin{tabular}{|l|}
0.578 \\
\end{tabular} \\
\hline TV4 & \begin{tabular}{|l|}
-0.106 \\
\end{tabular} & \begin{tabular}{|l|}
-0.148 \\
\end{tabular} & -0.157 & \begin{tabular}{|l|}
-0.194 \\
\end{tabular} & \begin{tabular}{|l|}
-0.140 \\
\end{tabular} & -0.128 & \begin{tabular}{|l|}
0.550 \\
\end{tabular} & 0.903 & \begin{tabular}{|l|}
0.605 \\
\end{tabular} \\
\hline TV5 & -0.136 & \begin{tabular}{|l|}
-0.101 \\
\end{tabular} & -0.079 & -0.174 & -0.076 & -0.060 & \begin{tabular}{|l|}
0.563 \\
\end{tabular} & 0.915 & 0.583 \\
\hline TV6 & \begin{tabular}{|l}
-0.139 \\
\end{tabular} & -0.080 & -0.116 & -0.182 & -0.103 & -0.112 & \begin{tabular}{|l|}
0.605 \\
\end{tabular} & 0.961 & 0.632 \\
\hline TV7 & \begin{tabular}{|l|}
-0.131 \\
\end{tabular} & \begin{tabular}{|l|}
-0.093 \\
\end{tabular} & -0.127 & -0.165 & \begin{tabular}{|l|}
-0.097 \\
\end{tabular} & -0.083 & \begin{tabular}{|l|}
0.590 \\
\end{tabular} & 0.954 & \begin{tabular}{|l|}
0.633 \\
\end{tabular} \\
\hline TV8 & -0.095 & \begin{tabular}{|l|}
-0.055 \\
\end{tabular} & -0.103 & -0.165 & -0.023 & -0.060 & \begin{tabular}{|l|}
0.528 \\
\end{tabular} & 0.917 & 0.628 \\
\hline TW1 & \begin{tabular}{|c|c|}
-0.103 \\
\end{tabular} & -0.084 & -0.064 & \begin{tabular}{|c|}
-0.170 \\
\end{tabular} & -0.091 & -0.086 & \begin{tabular}{|l|}
0.621 \\
\end{tabular} & 0.680 & \begin{tabular}{|l|}
0.917 \\
\end{tabular} \\
\hline TW2 & -0.083 & \begin{tabular}{|l|}
-0.114 \\
\end{tabular} & -0.073 & -0.212 & -0.128 & -0.098 & \begin{tabular}{|l|}
0.609 \\
\end{tabular} & 0.633 & 0.931 \\
\hline TW3 & -0.056 & -0.079 & -0.035 & \begin{tabular}{|l}
-0.228 \\
\end{tabular} & -0.115 & -0.051 & 0.592 & 0.584 & \begin{tabular}{|l|l|}
0.897 \\
\end{tabular} \\
\hline TW4 & -0.141 & -0.198 & -0.107 & -0.288 & -0.202 & -0.211 & \begin{tabular}{|l|}
0.667 \\
\end{tabular} & 0.605 & \begin{tabular}{|l|}
0.925 \\
\end{tabular} \\
\hline TW5 & -0.141 & -0.180 & -0.119 & -0.264 & -0.180 & -0.126 & \begin{tabular}{|l|}
0.664 \\
\end{tabular} & 0.586 & 0.930 \\
\hline TW6 & -0.150 & -0.135 & -0.083 & -0.229 & -0.168 & -0.129 & 0.662 & 0.604 & 0.949 \\
\hline
\end{tabular}




\section{APPENDIX B: MEASUREMENT ITEMS}

Alternative website quality (Li et al., 2006)

An alternative website is appealing.

An alternative website is better than this website.

To my knowledge, another website is closed to ideal.

An alternative website is attractive to me.

My needs could easily be fulfilled by an alternative website.

Customs duties cost [self-development]

If I bought a product from __, I worry that I will have to pay much money in additional import duties (customs tariffs) in my country.

If I bought a product from ___ I am uncertain about how much I will have to pay in additional import duties (customs tariffs) in my country.

Confiscation risk [self-development]

If I bought a product from ___ I worry that the product would be intercepted by authorities in my country before they reach me.

If I bought a product from __ I worry that the product would be confiscated by authorities in my country without compensation.

The risk that products purchased from __ will be confiscated is high.

If I bought a product from __. I worry that the product will not clear customs.

Delivery risk (Hong \& Cha, 2013)

If I bought a product from ___ I would be concerned as to whether the product would be delivered to the wrong address.

If I bought a product from ___ I would be concerned as to whether the product would be lost during delivery.

If I bought a product from __ I I would be concerned as to whether a wrong product would be delivered. If I bought a product from ___, I worry that the product will not be delivered due to aircraft refusal (e.g. the product has magnetism) [self-development]

If I bought a product from ___, I worry that the product would be damaged after shipping. [selfdevelopment]

Financial risk [self-development]

If I bought a product from __. I may suffer monetary loss due to fluctuations in exchange rates.

If I bought a product from __, I worry that I will face extra costs to ship to my city.

Privacy risk (Kim et al., 2009)

I am concerned that ___ is collecting too much personal information from me.

I am concerned that __ will use my personal information for other purposes without my authorization.

I am concerned that__ will share my personal information with others without my permission.

I am concerned that unauthorized persons (i.e. hackers) have access to my personal information.

I am concerned about the privacy of my personal information during a transaction.

Trust in vendor (adapted from Fang et al., 2014)

I believe that the vendor on is consistent in quality and service.

I believe that the vendor on is keen on fulfilling my needs and wants.

I believe that the vendor on is honest.

I believe that the vendor on wants to be known as one that keeps promises and commitments.

I believe that the vendor on has my best interests in mind.

I believe that the vendor on is trustworthy.

I believe that the vendor on

I believe that the vendor on has high integrity. is dependable.

Trust in website (Thatcher et al., 2013)

I think is very reliable. 
To me, is dependable. performs in a predictable way.

I think __ has the functionality I need. has the ability to do what I want it to do.

Overall, __ has the capabilities I need.

Repeat purchase intention (Chiu et al., 2014; Gefen, 2002)

I plan to continue using for cross-border purchase.

I consider __ to be my first choice for cross-border transactions in the future.

It is likely that I will continue purchasing products from in the future.

I would recommend to others.

I would encourage others to use

I am inclined to do more business with

\section{APPENDIX C: COMMON METHOD BIAS}

Harman's one-factor test is one of the widely employed techniques to test common method bias. The authors first checked for common method bias by performing this test (Podsakoff \& Organ, 2006). An exploratory factor analysis of all the scale items revealed factors explaining $77.8 \%$ of the variance in this study's constructs, with the first factor explaining $29.7 \%$, and the last explaining $3.0 \%$ of the total variance. These results suggest that no single factor explained a majority of the variance, thus supporting the idea that common method bias was not a threat to this study. Secondly, the authors followed the recommendations proposed by Rönkkö and Ylitalo (2011) using the PLS marker variable approach. The authors calculated the mean correlation between the marker items and the study items and found that the mean correlation is 0.06 , which is slightly higher than the recommended value of 0.05. Then, a method factor was also created using the marker indicators as an exogenous variable predicting endogenous construct in the model. The authors compared the method factor model with the baseline model and found that the significant paths in the baseline model remain significant in the method factor model. Hence, the PLS marker variable approach reveals that common method bias might not be a threat in the data of this study. In addition, the authors found the highest correlation is 0.689 , which is lower than the threshold value of 0.9 (Pavlou, Liang, \& Xue, 2007). In sum, all these evaluations indicate that the CMV is not a threat of this study.

\section{APPENDIX D: RELIABILITY AND VALIDITY}

The authors appropriately tested for the reliability and validity of the measurement model. The results, including mean, standard deviation (SD), average variance extracted (AVE), composite reliability (CR), and Cronbach's alpha value, are shown in Table 4. All items were loaded in their expected constructs with the value above 0.7 with the exception of AWQ1 (0.687) (see Appendix A). The AVE value for each construct was above the recommended threshold value of 0.5 . All construct reliabilities fit between $0.855-0.978$, exceeding the criterion of 0.7 . Therefore, composite reliability of the measurement model was confirmed. The Cronbach's alpha value was tested to verify the reliability. All Cronbach's alpha values were above the recommended value of 0.7. Using these benchmarks, the measurement model is suitable for subsequent analysis.

Table 5 shows the correlations between each construct. To prove discriminant validity of the model, the square root of AVE was compared with inter correlations of each construct. All the square roots of AVE exceeded the respective correlation; discriminant validity was confirmed. 
Table 4. Results of reliability, validity and means of the construct

\begin{tabular}{|c|c|c|c|c|c|c|}
\hline Variable & Items & Mean & S.D. & AVE & CR & Alpha value \\
\hline \multirow{5}{*}{$\begin{array}{l}\text { Alternative website quality } \\
\text { (AWQ) }\end{array}$} & AWQ1 & \multirow{5}{*}{3.051} & \multirow{5}{*}{0.853} & \multirow{5}{*}{0.690} & \multirow{5}{*}{0.917} & \multirow{5}{*}{0.893} \\
\hline & AWQ2 & & & & & \\
\hline & AWQ3 & & & & & \\
\hline & AWQ4 & & & & & \\
\hline & AWQ5 & & & & & \\
\hline \multirow{2}{*}{ Customer duties cost (CD) } & CD1 & \multirow{2}{*}{2.938} & \multirow{2}{*}{1.345} & \multirow{2}{*}{0.908} & \multirow{2}{*}{0.952} & \multirow{2}{*}{0.904} \\
\hline & $\mathrm{CD} 2$ & & & & & \\
\hline \multirow{4}{*}{ Confiscation risk (CR) } & CR1 & \multirow{4}{*}{2.694} & \multirow{4}{*}{1.301} & \multirow{4}{*}{0.846} & \multirow{4}{*}{0.956} & \multirow{4}{*}{0.951} \\
\hline & CR2 & & & & & \\
\hline & CR3 & & & & & \\
\hline & CR4 & & & & & \\
\hline \multirow{5}{*}{$\begin{array}{l}\text { Delivery risk } \\
\text { (DR) }\end{array}$} & DR1 & \multirow{5}{*}{2.626} & \multirow{5}{*}{1.094} & \multirow{5}{*}{0.706} & \multirow{5}{*}{0.923} & \multirow{5}{*}{0.897} \\
\hline & DR2 & & & & & \\
\hline & DR3 & & & & & \\
\hline & DR4 & & & & & \\
\hline & DR5 & & & & & \\
\hline & FR4 & & 1203 & 0751 & & 0781 \\
\hline Financial risk (FK) & FR5 & 2.656 & 1.203 & 0.151 & 0.855 & $0 . / 81$ \\
\hline & PC1 & & & & & \\
\hline & $\mathrm{PC} 2$ & & & & & \\
\hline Privacy risk (PC) & PC3 & 2.711 & 1.165 & 0.804 & 0.953 & 0.941 \\
\hline & PC4 & & & & & \\
\hline & PC5 & & & & & \\
\hline & RPI1 & & & & & \\
\hline & RPI2 & & & & & \\
\hline & RPI3 & & & & & \\
\hline Repurchase intentıon (RPI) & RPI4 & 3.957 & 1.060 & 0.850 & 0.971 & 0.964 \\
\hline & RPI5 & & & & & \\
\hline & RPI6 & & & & & \\
\hline & TV1 & & & & & \\
\hline & TV2 & & & & & \\
\hline & TV3 & & & & & \\
\hline & TV4 & 3500 & & & & \\
\hline Irust in provider (IP) & TV5 & 3.500 & 1.056 & 0.850 & 0.978 & 0.975 \\
\hline & TV6 & & & & & \\
\hline & TV7 & & & & & \\
\hline & TV8 & & & & & \\
\hline & TW1 & & & & & \\
\hline & TW2 & & & & & \\
\hline Truet in white (TW) & TW3 & 3770 & & & & \\
\hline 1rust in website (1 w) & TW4 & 3.170 & 0.989 & 0.855 & 0.913 & 0.966 \\
\hline & TW5 & & & & & \\
\hline & TW6 & & & & & \\
\hline
\end{tabular}


Table 5. Construct correlations (Diagonal bold values are square root of AVE)

\begin{tabular}{|l|l|l|l|l|l|l|l|l|l|}
\hline & \multicolumn{1}{|c|}{ AWQ } & CD & CR & DR & FR & PC & RPI & TV & TW \\
\hline AWQ & $\mathbf{0 . 8 3 1}$ & & & & & & & & \\
\hline CD & 0.295 & $\mathbf{0 . 9 5 3}$ & & & & & & & \\
\hline CR & 0.262 & 0.608 & $\mathbf{0 . 9 2 0}$ & & & & & & \\
\hline DR & 0.311 & 0.492 & 0.603 & $\mathbf{0 . 8 4 0}$ & & & & & \\
\hline FR & 0.291 & 0.561 & 0.510 & 0.539 & $\mathbf{0 . 8 6 7}$ & & & & \\
\hline PC & 0.315 & 0.368 & 0.486 & 0.541 & 0.425 & $\mathbf{0 . 8 9 7}$ & & & \\
\hline RPI & -0.263 & -0.143 & -0.128 & -0.317 & -0.155 & -0.172 & $\mathbf{0 . 9 2 2}$ & & \\
\hline TV & -0.133 & -0.099 & -0.113 & -0.202 & -0.106 & -0.096 & 0.609 & $\mathbf{0 . 9 2 2}$ & \\
\hline TW & -0.123 & -0.144 & -0.088 & -0.252 & -0.161 & -0.128 & 0.689 & 0.665 & $\mathbf{0 . 9 2 5}$ \\
\hline
\end{tabular}

Jian Mou is a Lecturer of the School of Economics and Management, Xidian University. His research interests include e-commerce, human computer interaction, trust and risk issues in e-service and the dynamic nature in systems use. His research has been published in Computers in Human Behavior, Electronic Commerce Research, Information Development, Behaviour and Information Technology, IT \& People, International Journal of Human-Computer Interaction and Information Technology and Tourism, as well as in the proceedings such as ICIS, ECIS and PACIS.

Yi Cui is a lecturer of School of Economics and Management, Communication University of China. His research focuses on electronic commerce, organizational culture and technology adoption.

Kerry Kurcz earned a Bachelor of Science in Information and Decision Science from the University of Illinois at Chicago in 2018. Shortly after graduation, she started working for Chicago-based insurance company CNA as a data engineer and application developer. 